\title{
Introduction to Issue 4 of 2019, World Nutrition
}

Ted Greiner, Editor-in-Chief

This, the fourth issue of World Nutrition for 2019, covers a wide range of issues central to public health nutrition. It includes the winners of the paper writing contest that the World Public Health Nutrition Association held over the past half year for scholarships to attend its Congress in Australia three months from now (https://www.wphncongress2020.com/). The deadline for applying for other scholarships is January 19.

The Latin American paper writing contest winner is from Rincon et al, on the impressive front of pack labeling systems spreading through that region. They explore three types of labels and reveal which is preferred by the most vulnerable families in four Latin American countries.

The Africa winner is a paper by Jonah and May exploring inequality in diets in South Africa and its links with income and assets, based on data from the latest national dietary survey (which are all too rare in most countries).

The Asia winner is a paper by Rana and Schellenberg, measuring the impact of an addition of micronutrient specific interventions within an area benefiting from the impressive, large-scale Shiree poverty alleviation project in Bangladesh.

WN readers interested in the history, politics, and philosophies behind how public health nutrition in low-income countries has been evolving over the past half century will find the paper by Harris fascinating and provocative.

Also at his most provocative, our Deputy Editor George Kent, in his Good Questions article this time, asks if hunger is not similar to genocide. His review of Eyal Mayroz's book, Reluctant Interveners, suggests that responses to hunger and genocide have been similar.

Schuftan reminds us that research, advocacy and action all must involve the most vulnerable communities, providing us with a "how to" perspective.

Shrimpton reminds us that we are literally facing climate change extinction and transformation of our food systems is receiving far too little attention in the growing global efforts to save our planet.

Most public health nutrition practitioners are educated in the natural sciences and more familiar with quantitative than qualitative research methods. I am among them. Although I did study qualitative methods, I felt it would be a disservice to the social scientific field to allow my graduate students to use them exclusively. Using them to triangulate was however a good thing, as I believe that often improves the validity of research projects that are otherwise quantitative. In this issue, Leepile provides WN readers with an up to date and in-depth review of the qualitative research methods in use in our field.

As Harris points out in her paper, nutritional stunting is now receiving a good deal of attention. Personally, I believe that is a good thing--after so much magic bullet spending on RUTF and 
micronutrients. In this issue, Ettyang et al explore factors associated with stunting in Kenya and Cambodia. They find several determinants, but the ways the Demographic and Health Surveys measure gender equality are not one of them.

Ramirez et al compare results of nutrition surveillance data from one region in the Philippines with data from a survey. While they find differences, the remind us that nutrition surveillance has other important objectives, even if its estimates of levels of malnutrition are apparently not always accurate.

A letter to the editor from Dadich et al warns that some countries have misunderstood the WHO target for increasing exclusive breastfeeding and offer assistance to solve this problem. 